OPEN ACCESS

Edited by:

Li Shuai,

Fujian Agriculture and Forestry

University, China

Reviewed by:

Xun $\mathrm{Hu}$,

University of Jinan, China

Kwang Ho Kim,

Korea Institute of Science and

Technology (KIST), South Korea

Yuan Xue,

Shanghai Jiao Tong University, China

${ }^{*}$ Correspondence:

Haoxi Ben

benhaoxi@gmail.com

Specialty section:

This article was submitted to Bioenergy and Biofuels,

a section of the journal

Frontiers in Energy Research

Received: 04 March 2020

Accepted: 14 April 2020

Published: 27 May 2020

Citation:

Wang $R$ and Ben H (2020) Accelerated Aging Process of Bio-Oil

Model Compounds: A Mechanism Study. Front. Energy Res. 8:79. doi: 10.3389/fenrg.2020.00079

\section{Accelerated Aging Process of Bio-Oil Model Compounds: A Mechanism Study}

\author{
Rui Wang ${ }^{1,2}$ and Haoxi Ben ${ }^{1,2 *}$ \\ ${ }^{1}$ School of Energy and Environment, Southeast University, Nanjing, China, ${ }^{2}$ Key Laboratory of Energy Thermal Conversion \\ and Control, Ministry of Education, Nanjing, China
}

Bio-oil, obtained from the pyrolysis of biomass, is identified as a potential material for producing transportation fuels and value-added chemicals. However, the physical and chemical properties of bio-oil change with time, known as "aging," and the instability of bio-oil brings a critical hurdle to the commercial application of bio-oil. Therefore, expanding and deepening the understanding of the aging mechanism of bio-oil is the key to later efficient application of bio-oil. In addition, the extreme complexity of pyrolysis bio-oil composition brings great difficulties in studying the aging mechanism. Thus, this study tries to better understand the aging mechanism by evaluating the aging performance for 39 model compound aging tests performed at $80^{\circ} \mathrm{C}$ for $72 \mathrm{~h}$. Four kinds of reactions (self-condensation, esterification, aldol condensation, and phenol, and aldehyde reaction) were investigated to understand the contribution of various compounds and reactions during the aging process. It has been found that acids played an important role in the aging process, as these acted as the reactant in the esterification reaction and acted as the catalyst for aldol condensation and phenol and aldehyde reaction. Acids and alcohols reacted via the esterification reaction, resulting in the decline of aliphatic C-O bonds. Due to the absence of acids, aromatic compounds were relatively stable in these tests. In comparison, aldehydes and HMF were active since self-condensation reactions for these chemicals were observed in the absence of acids. Moreover, with the aid of acids, HMF showed high tendency toward polymerization during the accelerated aging process.

\section{Keywords: bio-oil, aging mechanism, model compounds, ${ }^{1} \mathrm{H}$ NMR, accelerated aging process}

\section{INTRODUCTION}

Biomass is viewed as a promising renewable energy source, which can produce various forms of biofuels and biomaterials without contributing to new $\mathrm{CO}_{2}$ in the atmosphere (Ragauskas, 2006; Yang et al., 2015). Among different types of conversion methods for biomass, pyrolysis, performed in an anaerobic environment, is one of the most effective and convenient strategies to convert biomass feedstock into useful products (Zhang et al., 2018). Bio-oil, derived from the thermal breakdown of cellulose, hemicellulose, tannin, and lignin, is a mixture of multiple organic substances. Moreover, bio-oil, with characteristics of low sulfur and nitrogen, is considered the precursor of biofuel, owing to its relatively high energy density and ease of transportation and storage. 
However, the application of bio-oil is limited due to a number of undesirable properties; one is its aging problem, which results in chemical and physical changes of bio-oil such as high and changing water content, acidity, and molecular weight. Due to the dehydration reaction during the pyrolysis process, typically, pyrolysis bio-oil contains relatively high levels of water content, and the water content increases during biooil storage as water is produced by bio-oil aging reactions (Chaala et al., 2004). Chemically, bio-oil has high acidity ( $\mathrm{pH}$ 2-3) (Alsbou and Helleur, 2014), and this acidic environment and the various organic compounds present in bio-oil play an important role in the bio-oil aging process. Therefore, several upgrading processes have been applied to optimize the deleterious properties of pyrolysis oil. The upgrading technologies, including hydrodeoxygenation (HDO), catalytic cracking, hydrogenation (HYD), and selective ring opening (SRO), show strong abilities to improve the quality of raw bio-oil, since these technologies can convert oxygen-enriched pyrolysis oil into renewable fuels and increase the content of valuable chemicals in bio-oil (Ma et al., 2018; Ben et al., 2019). However, it was found that during the hydrodeoxygenation process, polymerization, and hydrogenation have comparative reaction rates and even the polymerization process is relatively faster than the hydrogenation process, which could result in the deactivation of catalysts and bring more difficulties in the upgrading process (Hu et al., 2013; Luo et al., 2018). Therefore, expanding the knowledge of the bio-oil aging process, which brings changes in the physical and chemical properties of bio-oil and bring more problems in the upgrading process, is important for later application of bio-oil and the upgrading process. The study of the aging process of raw bio-oil can help understand how and why aging occurs, which later is crucial in taking any possible actions to plan for the upgrading process of bio-oil. To reveal the underlying mechanism of the aging process, great efforts have been made. Meng et al. (2014) proposed that the increasing temperature and presence of acids are responsible for the increase in the molecular weight of bio-oil. Increasing water content is observed during the aging process, as water is a by-product of the condensation reaction (Joseph et al., 2016). Reactive substances such as aldehydes, alcohols, and olefins reacting via the condensation reaction result in chemical changes of bio-oil (Alsbou and Helleur, 2014). This knowledge plays a very important role in expanding our understanding of aging and studying the aging process of bio-oil. However, the extreme complexity of bio-oil has brought great difficulties in studying the aging of bio-oil since there are more than 300 chemicals in bio-oil, and the aging mechanism of bio-oil is still not totally understood. Compared with the complex environment of biooil, the model compound simplifies the aging process of bio-oil, which is beneficial in analyzing the changes of single substances. Therefore, applying model compounds in bio-oil aging study helps provide more insights into the bio-oil aging mechanism at the molecular level, which few studies focused on.

In this work, an investigation on bio-oil aging reactions at a specified temperature has been performed to reveal the contribution of main reactive compounds and main reactions that cause bio-oil aging. To simplify and get specific information about the bio-oil aging mechanism, a number of model compounds representing the bio-oil derived from the cellulose and hemicellulose part and bio-oil derived from the lignin and tannin part were applied in this study. The use of these model compounds offer advantages for elucidating the role of each compound during the aging process. Additionally, deepening the understanding of this is essential in stabilizing bio-oil and optimizing the desirable properties of bio-oil.

\section{EXPERIMENTAL SECTION}

\section{Materials}

Hundreds of ingredients, produced from major components of biomass - lignin, tannin, cellulose, and hemicellulose - are found in bio-oil, which complicates the aging mechanism of bio-oils. Cellulose and hemicellulose make a significant contribution to sugar and sugar derivative formation, and lignin, and tannin are the main sources of aromatics (Wu et al., 2009; Ben and Ragauskas, 2011; Qu et al., 2011; Kibet et al., 2012; Vinu and Broadbelt, 2012; Mu et al., 2013; Huang et al., 2014). Therefore, a series of typical bio-oil model compounds, which are divided into two categories, cellulose and hemicellulose part (Figure 1A) and lignin and tannin part (Figure 1B), was chosen to simplify and get specific information about the biooil aging mechanism. 5-Hydroxymethylfurfuraldehyde (HMF), 2-furaldehyde (furfural), hydroxyacetone, glycolaldehyde dimer, and 4-allyl-2-hydroxybenzaldehyde contain more than one oxygen-containing functional group, which activates these compounds during the aging process. Therefore, these substances are individually heated for aging experiments named selfcondensation test. Ben and Ragauskas (2012) observed a decrease in aliphatic $\mathrm{C}-\mathrm{O}$ bonds and aromatic $\mathrm{C}-\mathrm{H}$ bonds and an increase in aliphatic $\mathrm{C}-\mathrm{C}$ bonds and aromatic $\mathrm{C}-\mathrm{C}$ and $\mathrm{C}-\mathrm{O}$ bonds during the accelerated aging process for various types of bio-oils at $80^{\circ} \mathrm{C}$. Alcohols and acids, present in large quantities in bio-oil, can react via the esterification reaction, which consumes $\mathrm{C}-\mathrm{O}$ bonds. It is well known that bio-oil has high acidity, and novolak resin and water could be formed since aldehyde hydrates can react with phenols and substituted phenols under acidic conditions (Yu et al., 2018). This reaction leads to increases in C-C bonds and water content, which affect the aging performance of biooil. Moreover, aldol condensation is catalyzed by acids, during which the number of $\mathrm{C}=\mathrm{O}$ bonds declines and the number of C-C bonds increases (Patil and Lund, 2011; Patil et al., 2012; $\mathrm{Hu}$ et al., 2013). Therefore, four kinds of reactions (Figure 2), self-condensation, esterification, aldol condensation, and phenol and aldehyde reaction, were employed to study the bio-oil aging mechanism and the roles of all these reactions. All experimental materials used in this study were bought from Sigma-Aldrich and were used directly without further processing.

\section{Experimental Procedure}

The experiment was performed in a $2 \mathrm{ml}$ threaded brown sample vial $\left(11.6^{*} 32 \mathrm{~mm}\right)$. Typically, model compounds (0.001 mole for each model compound) were mixed 1: 1 (by mole) and loaded in the sample vial at room temperature. The mouth of the sample vial was sealed to ensure that the internal materials would not 
A<smiles>O=Cc1ccc(CO)o1</smiles>

HMF<smiles>O=CC(O)CO</smiles>

Glyceraldehyde<smiles>O=Cc1ccco1</smiles>

2-Furaldehyde<smiles>OC1COC(O)CO1</smiles>

Glycolaldehyde Dimer
Cellulose and hemicellulose part<smiles>OCc1ccco1</smiles>

Furfuryl alcohol

Hydroxyacetone<smiles>O=CO</smiles>

Formic acid<smiles>OC1C2COC(O2)C(O)C1O</smiles>

Levoglucosan<smiles>CC(=O)O</smiles>

Acetic acid
B<smiles>Oc1ccccc1</smiles>

Phenol<smiles>C=CCc1ccc(O)c(OC)c1</smiles>

4-allyl-2-methoxyphenol<smiles>Oc1ccccc1O</smiles>

Catechol

\section{lignin and tannin part}<smiles>Cc1cccc(O)c1O</smiles>

3-Methylcatechol<smiles>COc1ccccc1O</smiles>

Guaiacol<smiles>COc1cccc(OC)c1O</smiles>

2,6-Dimethoxyphenol<smiles>COc1cc(C(C)=O)cc(OC)c1O</smiles>

3',5'-Dimethoxy-4'-Hydroxyacetophenone<smiles>COc1cc(C=O)ccc1O</smiles>

$$
\text { Methanol }
$$<smiles>COc1cc(C=O)cc(OC)c1O</smiles>

3,5-Dimethoxy-4-Hydroxybenzaldehyde<smiles>COc1cc(C(=O)O)ccc1O</smiles>

4-Hydroxy-3-Methoxybenzoic Acid

FIGURE 1 | Model compounds for the (A) cellulose and hemicellulose part and (B) lignin and tannin part.

overflow during the experiment process and the external gas would not affect the reaction. Then, the vial was placed in an oil pan and heated at $80^{\circ} \mathrm{C}$ for $72 \mathrm{~h}$ (Diebold and Czernik, 1997; Oasmaa and Kuoppala, 2003; Elliott et al., 2012; Meng et al., 2014). All model compound aging tests were repeated three times to ensure accuracy.

\section{Analytical Method}

${ }^{1} \mathrm{H}$ NMR Analysis

The products were analyzed by using a Bruker Avance/DMX $400 \mathrm{MHz}$ NMR spectrometer. Quantitative ${ }^{1} \mathrm{H}$ NMR results were acquired with eight transients and a 5-s pulse delay.
The MestReNova software was used to analyze the results of the experiments. In addition, the MestReNova software has the capacity to predict the ${ }^{1} \mathrm{H}$ NMR results of model compounds, which allows us to compare the changes in the model compounds before and after aging to clarify the aging mechanism. However, during the data analysis process, the inaccuracy of some ${ }^{1} \mathrm{H}$ NMR predictions of model compounds was found. In order to correct these errors, additional quantitative ${ }^{1} \mathrm{H}$ NMR tests of HMF, glycolaldehyde dimer, furfural, hydroxyacetone, levoglucosan, furfuryl alcohol, 4-allyl-2-hydroxybenzaldehyde, and glyceraldehyde were performed. 
A<smiles>O=Cc1ccc(CO)o1</smiles>

ST1

B<smiles>O=C(O)CC1C2OCCC(O2)C1O</smiles><smiles>O=COC1C(O)C2COC(O2)C1O</smiles><smiles>COc1ccc(C(=O)O)cc1OCc1ccccc1</smiles>

C

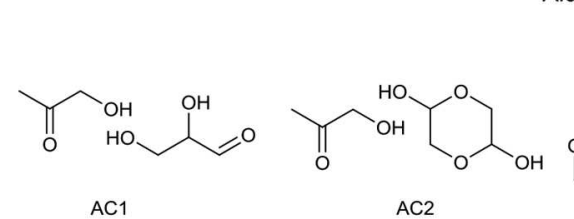

Ald<smiles>O=Cc1ccco1</smiles>

ST3

\section{Esterification test}<smiles>COc1cc(C(=O)O)ccc1O</smiles><smiles>O=Cc1ccc(CO)o1</smiles><smiles>CC(=O)CO</smiles>

ST4<smiles>C=CCc1ccc(O)c(OC)c1</smiles>

ST5<smiles>COc1cc(C(=O)O)ccc1OCO</smiles><smiles>O=C(O)Cc1ccco1</smiles>

ET9<smiles>COc1ccc(C=O)cc1O</smiles>

$\mathrm{AC4}$
$\underbrace{\mathrm{ET5}}_{\mathrm{O}}$

ET10<smiles>CC(=O)CO</smiles><smiles>COc1cc(C=O)cc(OC=O)c1Oc1ccco1</smiles>

Phenol and aldehyde reaction test<smiles>COc1cccc(OCC(O)C=O)c1OCC(O)Oc1cccc(OC)c1OCC(O)COC1COC(O)CO1</smiles>

D<smiles>COc1ccccc1O</smiles><smiles>COc1cc(C=O)cc(OC)c1O</smiles><smiles>COc1cc(C=O)cc(O)c1O</smiles><smiles>O=Cc1ccc(CO)o1</smiles><smiles>O=Cc1ccc(-c2cccc(O)c2)o1</smiles>

PA6 PA7

PA8

PA9<smiles>O=Cc1ccc(CO)o1</smiles>

PA11<smiles>Cc1cccc(O)c1O</smiles>

PA12<smiles>COc1cccc(CO)c1OCc1ccc(C=O)o1</smiles>

PA13<smiles>COc1cccc(OC)c1O</smiles>

PA14

PA10<smiles>O=Cc1ccc(Oc2ccccc2O)o1</smiles>

FIGURE 2 | Specific details of the (A) self-condensation test, (B) esterification test, (C) aldol condensation test, and (D) phenol and aldehyde reaction test (all experiments were heated at $80^{\circ} \mathrm{C}$ for $72 \mathrm{~h}$ ). 


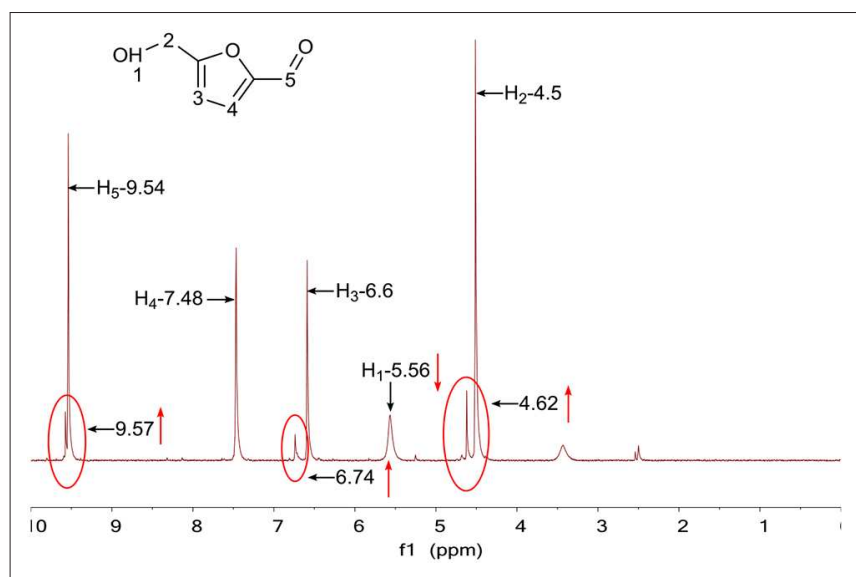

FIGURE $3 \mid{ }^{1} \mathrm{H}$ NMR results for HMF after the aging process.

\section{GC-MS Analysis}

A Shimadzu GC-MS (GCMS-QP2010 SE) spectrometer was used to analyze the products. During the analysis process, the initial temperature was set as $40^{\circ} \mathrm{C}$, and this temperature was maintained for $4 \mathrm{~min}$. Later, the temperature was increased to $250^{\circ} \mathrm{C}$ at a heating rate of $25^{\circ} \mathrm{C} / \mathrm{min}$. Each compound was identified by comparing its mass spectrum with the standard mass spectrum in the spectral library.

\section{RESULTS AND DISCUSSION}

\section{Self-Condensation Test}

${ }^{1} \mathrm{H}$ NMR results for HMF before and after the accelerated aging process for $72 \mathrm{~h}$ are provided in Figure S1 and Figure 3. Different from HMF that did not undergo aging processing, the aged HMF had three more peaks (4.62, 6.74, and 9.57 ppm) in the ${ }^{1} \mathrm{H}$ NMR spectrum, which were slightly shifted to the left compared with the original peaks $(4.51,6.59$, and $9.54 \mathrm{ppm})$. These left-shifted peaks indicate that the overall structure of HMF did not change a lot, and only a part of the structures reacted. In addition, a decrease of the peak at $5.56 \mathrm{ppm}$, representing the hydroxyl functional groups of HMF, was observed after the aging process. This reduced functional group content is evidence that the hydroxyl functional group was chemically active and reacted with other parts of HMF. Table S1 lists the identified compounds in HMF aging; it could be found that HMF decreased in abundance with aging. In contrast, 2,5furandicarboxaldehyde and cirsiumaldehyde had an increase in abundance, and cirsiumaldehyde was the dehydration product of HMF, which is consistent with the observation of a decrease in hydroxyl groups found in ${ }^{1} \mathrm{H}$ NMR results.

For the glycolaldehyde dimer, significant changes have taken place in this chemical after the aging process. When comparing the spectra of the glycolaldehyde dimer before (Figure 4A) and after (Figure 4B) the aging process, it can be seem that all hydrogen signals for the glycolaldehyde dimer greatly decreased. In addition, after careful comparison of the ${ }^{1} \mathrm{H}$ NMR results before and after the aging process, it can be observed that the peaks of the aged glycolaldehyde dimer coincided with the peaks of the original impurities in the glycolaldehyde dimer (Figure 4C depicts an enlarged view of the bottom of the glycolaldehyde dimer spectrum, showing the peaks for impurities in the glycolaldehyde dimer), which suggests that almost no glycolaldehyde dimer was left after the aging process and polymerization may occur between glycolaldehyde dimers.

Interestingly, different from HMF and the glycolaldehyde dimer, although furfural, hydroxyacetone, and 4-allyl-2hydroxybenzaldehyde have many active functional groups such as hydroxyl and carbonyl, these substances were stable after the aging process. ${ }^{1} \mathrm{H}$ NMR results before and after the aging process for furfural, hydroxyacetone, and 4-allyl-2-hydroxybenzaldehyde are listed in Figures S2-S7.

\section{Esterification Test}

In the case of ET1 (Figure 5A) and ET2 (Figure 5B), levoglucosan $\left({ }^{1} \mathrm{H}\right.$ NMR result for levoglucosan without the aging process is shown in Figure S8) was mixed with acetic acid or formic acid; the disappearance of hydroxyl groups $(4.77,4.83$, and $4.90 \mathrm{ppm})$ was observed and number of new peaks appeared. Although hydrolysis was the main reaction for levoglucosan to form glucose, this product appeared only when the temperature exceeded $90^{\circ} \mathrm{C}$ ( $\mathrm{Hu}$ et al., 2013), which suggests that levoglucosan reacted with acids as the alcohol at $80^{\circ} \mathrm{C}$. Therefore, these three disappearing peaks and new peaks represent the occurrence of the esterification reaction. The number of aliphatic $\mathrm{C}$-O bonds was greatly reduced due to the esterification reaction of levoglucosan, present in high abundance in pyrolysis (Helle et al., 2007; Yu et al., 2016).

ET5 examined the aging performance of the mixture of HMF and acetic acid, and the result is depicted in Figure 5C. It is shown in the spectrum that parts of the peak at $2.08 \mathrm{ppm}$ for acetic acid and the peak at $9.54 \mathrm{ppm}$ for HMF were shifted to the left side of their original peaks, meaning that both these substances were involved in the reaction. Moreover, these leftshifted peaks coincided with the peaks of the methyl (2.14 ppm) and carbonyl groups (9.61 ppm) on the esterification products of HMF and acetic acid, which was the evidence of the occurrence of the esterification reaction between these two reactants. Interestingly, in the case of ET8 (Figure 5D), although 4-hydroxy-3-methoxybenzoic acid contains a carboxyl group, no esterification reaction was observed between this substance and HMF. In this case, 4-hydroxy-3-methoxybenzoic acid was stable and the change of HMF was the same as the change of HMF aged alone, representing that the addition of 4-hydroxy-3-methoxybenzoic acid had no effect on HMF. In the presence of acetic acid, furfuryl alcohol (the ${ }^{1} \mathrm{H}$ NMR result for furfuryl alcohol without aging processing is shown in Figure S9, and the result for ET9 is shown in Figure 5E) was catalyzed to polymerize, as all signals for furfuryl alcohol greatly declined compared with the signals for acetic acid. Under the catalysis of acids, a carbocation would be formed from furfuryl alcohol, attaching another furfuryl alcohol via the electrophilic substitution reaction, as presented in Figure 6A (Hu et al., 2013). HMF was catalyzed by formic acid toward polymerization since no HMF was left after aging treatment 


\section{A after aging process}<smiles>OC1COC(O)CO1</smiles>

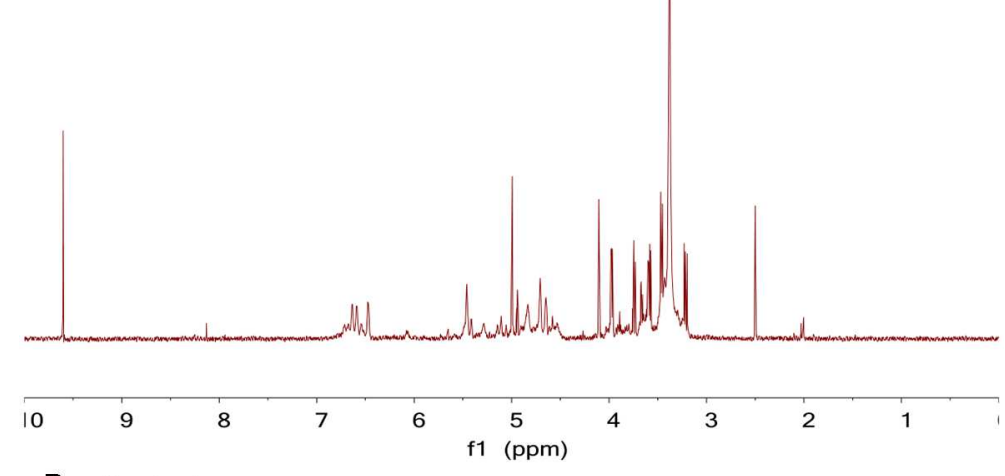

B without aging process
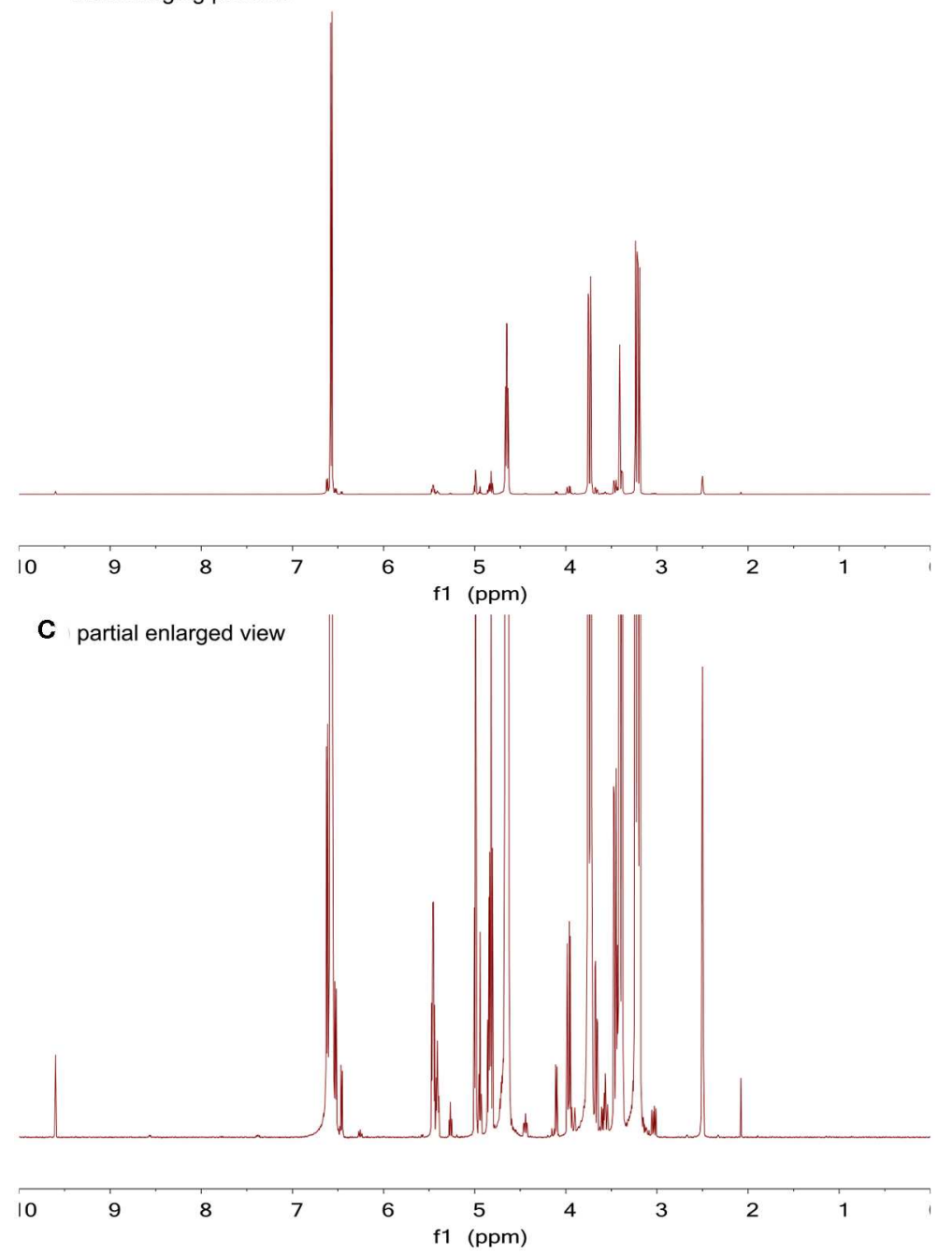

FIGURE 4 | (A) ${ }^{1} \mathrm{H}$ NMR results for the glycolaldehyde dimer after the aging process, (B) ${ }^{1} \mathrm{H}$ NMR results for the glycolaldehyde dimer without the aging process, and (C) an enlarged view of the bottom of the glycolaldehyde dimer spectrum. 


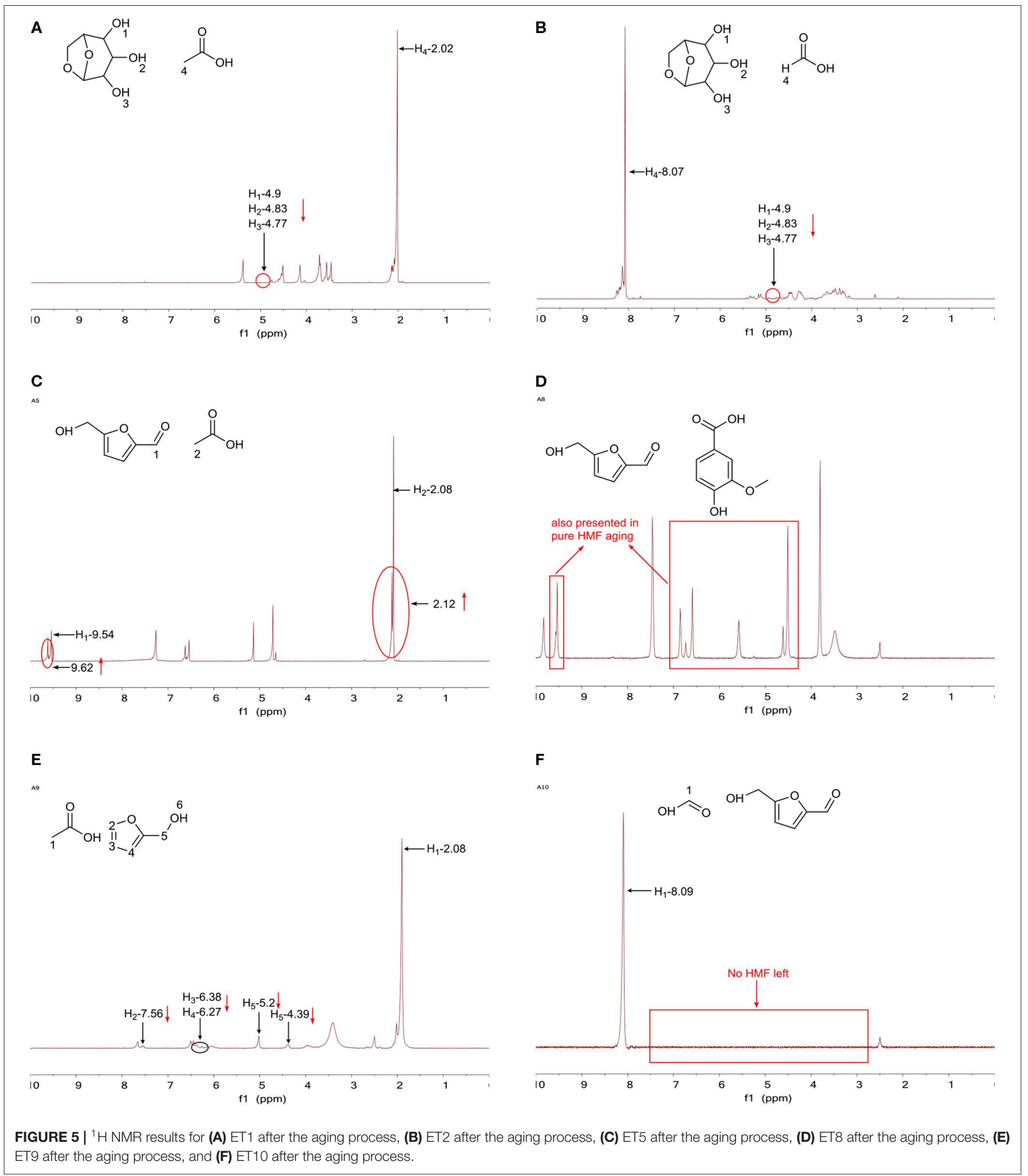

(Figure 5F). In addition, the formation of humins, a kind of darkcolored and tarry solids, was observed during the aging process. Patil et al. (2012) discovered the most likely pathway for humin formation, which showed that under acid catalysis, HMF formed 2,5-dioxo-6-hydroxyhexanal ( $\mathrm{DHH})$, an important intermediate for humin growth, and later via aldol addition/condensation, polymerization between DHH and HMF occurred (Figure 6B). In addition, the acid only played the role of a catalyst and did 
A

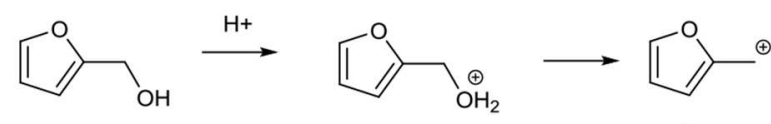<smiles>Cc1ccco1</smiles>

B<smiles>C[I+]I(C)CO</smiles><smiles>O=Cc1ccc(CO)o1</smiles>

FIGURE 6 | Reaction mechanism of (A) furfuryl alcohol in the presence of acetic acid and (B) HMF in the presence of formic acid.

not participate in the reaction since no reduction in formic acid hydrogen signals was observed. Almost no reaction occurred in the case of ET3, ET4, ET6, and ET7, and these results are presented in Figures S10-S13.

Comparing ET5, ET8, and ET10, it can be found that the reaction mechanisms of $\mathrm{HMF}$ with different acids were different. 4-Hydroxy-3-methoxybenzoic acid, formic acid, and acetic acid have different $\mathrm{pKa}$ values (acidity), which may be the reason for the different reaction mechanisms (Hu et al., 2013; Meng et al., 2014). Compared with formic acid and acetic acid, 4-hydroxy-3methoxybenzoic acid is so weak that it will not react with HMF. The acidity of acetic acid is stronger than that of 4-hydroxy-3methoxybenzoic acid but weaker than that of formic acid, and it undergoes esterification with HMF. Moreover, formic acid shows high acidity; it can catalyze HMF toward polymerization. A similar situation can be observed in ET6 and ET9. Thus, it can be hypothesized that furan derivatives containing hydroxyl groups such as HMF and furfuryl alcohol are active compounds in bio-oil and the reaction mechanism of these substances with acid changes with the acidity of the acid. With increasing acidity, the following reactions occur in order: no reaction, esterification (consume aliphatic C-O bond and form water), and condensation reaction (tend to polymerize and form water).

\section{Aldol Condensation Test}

As shown in Figure 7, reactions between glyceraldehyde (Figure S14) and hydroxyacetone were observed, as almost all peaks for glyceraldehyde disappeared and a decrease in the methyl peak of hydroxyacetone was observed (the integration of the peak at $4.03 \mathrm{ppm}$ : the integration of the peak at 2.03 $\mathrm{ppm}=1: 1.27)$. These changes also suggest that a condensation reaction may occur in the mixture via aldol condensation reaction since the dual functionality of glyceraldehyde and hydroxyacetone (aldehyde and alcohol) made these chemicals active toward condensation reactions. Hydroxyacetone and the glycolaldehyde dimer contain various active functional groups such as hydroxyl and carbonyl, and it seems that the reaction between these two chemicals is very easy. However, the ${ }^{1} \mathrm{H}$ NMR result (Figure S15) showed that these two substances did not react with each other after the 72 -h aging process. Although the hydroxyacetone and the glycolaldehyde dimer were mixed together, these two substances did not react with each other, and the spectrum of AC2 was like combining the spectra of aged hydroxyacetone and aged glycolaldehyde dimer together. ${ }^{1} \mathrm{H}$ NMR results for AC3, AC4, AC5, AC6, AC7, and AC8 are presented in Figures S16-S21, which show that these mixtures were stable after aging. Although phenolic compounds can be 


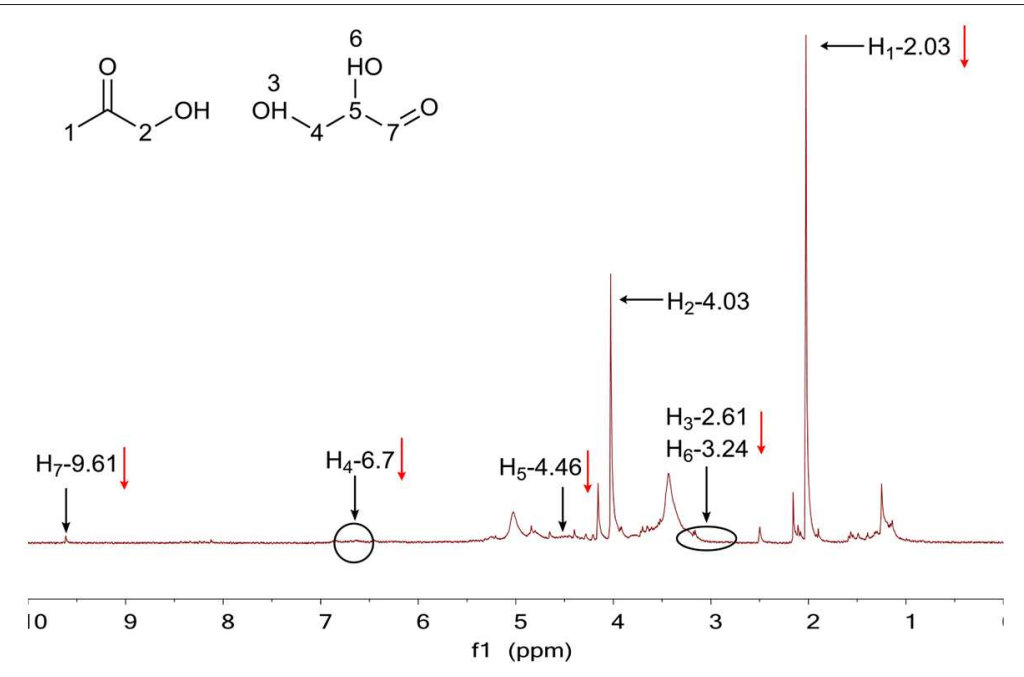

FIGURE $\left.7\right|^{1} \mathrm{H}$ NMR result for $\mathrm{AC} 1$ after the aging process.

regarded as weak acids, they are too weak to catalyze the aldol condensation reaction as shown in $\mathrm{AC} 3, \mathrm{AC} 4, \mathrm{AC} 7$, and $\mathrm{AC} 8$, suggesting that the presence of carboxylic acids may be the key to aldol condensation reactions (Patil and Lund, 2011; Patil et al., 2012). Interestingly, in AC5 and AC7 tests, no left-shifted peaks were discovered for HMF and almost no reaction occurred for it, indicating that HMF was relatively stable in these mixtures. The mechanism of this phenomenon is still unclear, and further research is needed.

Almost no obvious aldol condensation reaction was observed in these chosen tests; it seems that the acidic environment was very important during the reaction. The original low $\mathrm{pH}$ value of bio-oil and increasing acidity during the bio-oil aging process provided good reaction conditions for aldol condensation (Joseph et al., 2016; Jo et al., 2018), during which the number of $\mathrm{C}=\mathrm{O}$ bonds decreased. It was found that benzaldehyde could be added to HMF via aldol condensation during acid-catalyzed conversion, which demonstrates the possibility of increasing the values of humins (Patil and Lund, 2011). In addition, water was formed as a by-product of aldol condensation or other condensation reactions of aldehydes and ketones, explaining the increase in water during the aging process (Naske et al., 2012).

\section{Phenol and Aldehyde Reaction Test}

After the 72-h aging process, phenol was found to be stable in the PA1 test since the hydrogen signals for it did not change after aging treatment, which evidently meant that phenol did not react with glyceraldehyde, as shown in Figure 8A. Furthermore, the reaction for glyceraldehyde itself is observed in Figure $\mathbf{8 A}$, but to a limited extent, as the peaks for glyceraldehyde (2.50, $3.23,4.52$, and $9.63 \mathrm{ppm}$ ) decreased and a few small new peaks $(1.0-5.5 \mathrm{ppm})$ appeared in the spectrum. Due to the dual functionality of glyceraldehyde (alcohol and aldehyde), different kinds of reactions would occur, which could explain the appearance of these new peaks. Moreover, although phenol could play the role of a weak acid, no cross-linking reaction was found in the PA1 test, indicating that phenol was too weak to catalyze the reaction. The same phenomenon was also found in PA3 (Figure 8B) and PA5 tests (Figure 8C), where phenolic compounds were stable and glyceraldehyde had the same peak distribution as that of glyceraldehyde in PA1. Thus, all these three tests indicated that the reaction between phenol and aldehyde required strong acids or a higher temperature $\left(>80^{\circ} \mathrm{C}\right)$. From the ${ }^{1} \mathrm{H}$ NMR results of PA2 (Figure S22), PA4 (Figure S23) and PA6 (Figure S24), it could be concluded that phenolic components would not react with the glycolaldehyde dimer and they have no catalytic effect on the glycolaldehyde dimer, as the spectra of these three tests, after removing the hydrogen signals for phenolic compounds from the spectra, were basically consistent with the spectrum of the glycolaldehyde dimer self-condensation test. No more reaction was found in PA7-16, presented in Figures S25-S34. However, the stability of HMF was also discovered in PA9, PA11, PA13, and PA15, which was the same as the observation in AC5 and AC7. To examine whether HMF is stable in phenolic mixtures, an additional GC-MS test has been done for the aging test of the mixture of HMF and guaiacol. Table S2 lists the identified compounds in PA15 aging; from the analysis, it can be seen that HMF is stable in guaiacol, a typical model compound for lignin pyrolysis bio-oil. Therefore, it can be suggested that it is easy for HMF to maintain stability in phenolic mixtures.

Same as the aldoll condensation test part, due to the absence of an acid catalyst, no obvious reaction between phenol and aldehyde was found in this section. It is well known that with the aid of an acid, the formation of phenolic resins could be observed from the reaction between phenol and formaldehyde, furfural, or HMF, and this could be the reason for the increase in $\mathrm{C}-\mathrm{C}$ bonds and the decrease in $\mathrm{C}=\mathrm{O}$ bonds. In addition, under the catalysis of a proper acid, glycolaldehyde was found to react with phenol to a limited extent (Meng et al., 2014). All this existing knowledge indicates that in the acidic environment of bio-oil, the phenol and aldehyde selected in this section are likely to react with each other, which could explain the increase in $\mathrm{C}-\mathrm{C}$ bonds and the decrease in $\mathrm{C}=\mathrm{O}$ bonds during the aging process. 
A

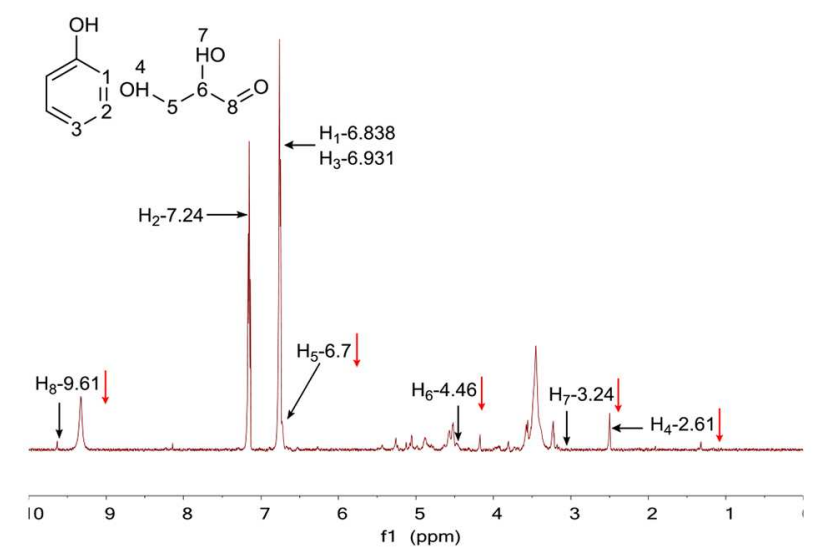

B

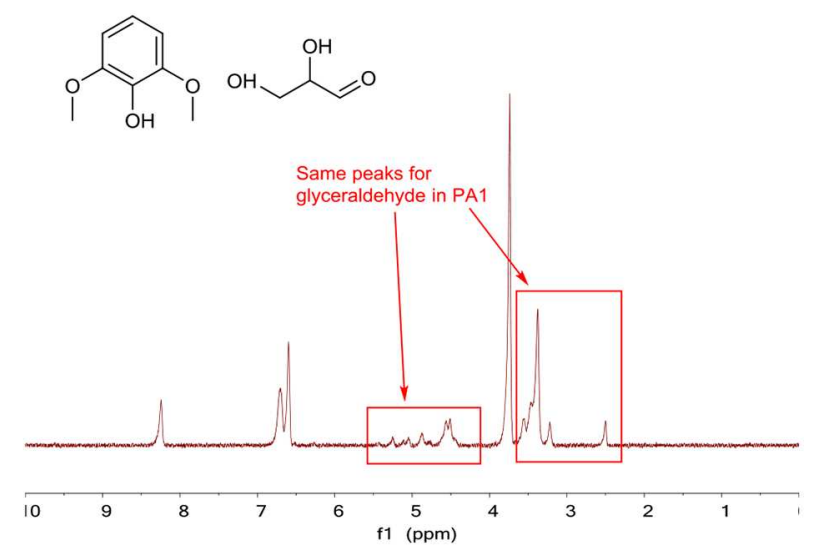

C<smiles>O=CC(O)COCc1ccccc1O</smiles>

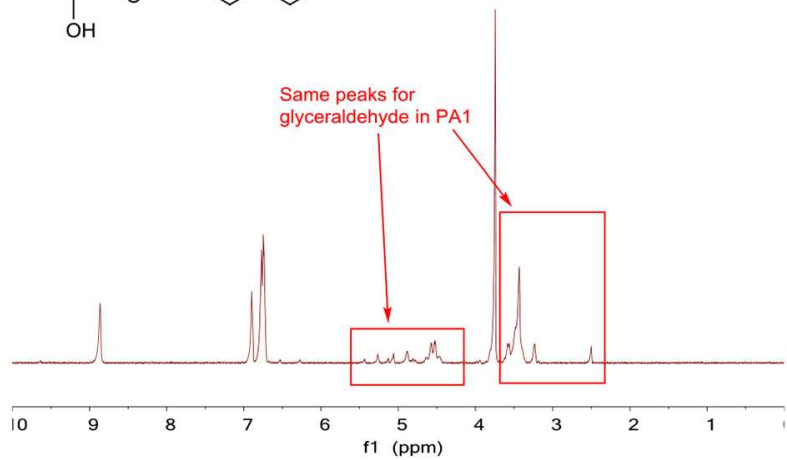

FIGURE $8 \mid{ }^{1} \mathrm{H}$ NMR results for (A) PA1 after the aging process, (B) PA3 after the aging process, and (C) PA5 after the aging process.

\section{The Role of Different Model Compounds}

Different kinds of model compounds played significantly different roles in various reactions. Acids, especially formic acid and acetic acid, were the most reactive compounds in bio-oil, as acids could act as both reactants and catalysts in various reactions. For example, at a low temperature $\left(80^{\circ} \mathrm{C}\right)$, formic acid can react with levoglucosan via esterification (Figure 6). In comparison, at a high temperature $\left(>90^{\circ} \mathrm{C}\right)$, it is well known that with the aid of formic acid, levoglucosan tends to undergo hydrolysis to form glucose and glucose further reacts to form small molecules (Hu et al., 2013). Due to the different acidities of different acids, their catalytic abilities present in reactions are also different. The ${ }^{1} \mathrm{H}$ NMR results of HMF in the presence of acetic acid, 4-hydroxy-3-methoxybenzoic acid, or formic acid are presented in Figures 5C,D,F. In addition, phenolic compounds, as a kind of weak acid, show little catalytic effect at a low temperature $\left(80^{\circ} \mathrm{C}\right)$. It can be concluded that removing acids from bio-oil and increasing the $\mathrm{pH}$ value of bio-oil would effectively slow the aging rate of bio-oil.

Aldehydes, sugars, and their derivatives, with different kinds of oxygen-containing functional groups, are the main components of bio-oils produced by pyrolysis of cellulose and hemicellulose, which contribute a lot to the aging of bio-oil. From the experiments above, HMF and the glycolaldehyde dimer are found to be highly reactive compounds in bio-oil, since reactions can be observed when these two substances are heated alone. Moreover, for furan and furan derivatives, with the presence of proper acids, these chemicals showed high tendency toward polymerization, which is closely related to the furan ring that they have. Moreover, under the catalysis of acid, a condensation reaction such as aldol condensation reaction can be observed for aldehyde, resulting in a decrease in $\mathrm{C}=\mathrm{O}$ bonds and increases in the water content and molecular weight of bio-oil.

Aromatic compounds are found to relatively stable at a low temperature $\left(80^{\circ} \mathrm{C}\right)$. Although phenolic compounds can be viewed as weak acids, the catalytic effect of phenolic compounds is not obvious, which indicates that a higher temperature may be needed. Even aromatic compounds containing carboxyl groups do not show significant catalytic effect. However, with the proper treatment of acids, new C-C bonds formed between phenolic compounds and aldehydes can be found and this reaction would significantly accelerate the aging of bio-oil.

In the case of model compound aging tests, the aging mechanism of bio-oil was investigated at the molecular level, 
which was rarely studied. Due to the use of model compounds, reactive substances have been identified and some possible reaction pathways have been proposed. However, there are still shortcomings of this study since none of these aging reactions can be verified in bio-oil or a similar environment. For example, aldol condensation and phenol and aldehyde reaction are expected to occur in bio-oil during the aging process, but due to the absence of acids, no obvious reactions are found in this work. If acids are added in these two kinds of reactions, it can be expected that the number of $\mathrm{C}=\mathrm{O}$ bonds will decrease, as both of these two reactions consume $\mathrm{C}=\mathrm{O}$ bonds. Therefore, considering that bio-oil contains hundreds of compounds, more aging tests related to bio-oil should be examined in future research to gain more insights into the bio-oil aging mechanism.

\section{CONCLUSION}

To elucidate the roles of different components of bio-oil and various reactions that may occur in the bio-oil aging process, pyrolysis model compounds have been employed to explore more information about the aging process. Thirty-nine model compound aging tests have been chosen to deepen the understanding of aging mechanism, which were divided into four parts, self-condensation, esterification, aldol condensation, and phenol and aldehyde reaction, and these tests were performed at $80^{\circ} \mathrm{C}$ for $72 \mathrm{~h}$. It can be concluded from the experiments that small acids, aldehydes, and HMF are the most active molecules in the model compound study. Acids play an important role in aging process, as these can be used not only as a reactant but also as a catalyst for the reaction. Therefore, it can be concluded that acidity is an important factor affecting the aging process of bio-oil. In the esterification test section, a decrease in the number of aliphatic C-O bonds was observed since acids and alcohols reacted via the esterification reaction. Although in this

\section{REFERENCES}

Alsbou, E., and Helleur, B. (2014). Accelerated aging of bio-oil from fast pyrolysis of hardwood. Energ. Fuel. 28, 3224-3235. doi: 10.1021/ef500399n

Ben, H., and Ragauskas, A. J. (2011). Heteronuclear single-quantum correlationnuclear magnetic resonance (HSQC-NMR) fingerprint analysis of pyrolysis oils. Energ. Fuel. 25, 5791-5801. doi: 10.1021/ef201376w

Ben, H., and Ragauskas, A. J. (2012). In situ NMR characterization of pyrolysis oil during accelerated aging. ChemSusChem 5, 1687-1693. doi: $10.1002 /$ cssc. 201200429

Ben, H., Wu, Z., Han, G., Jiang, W., and Ragauskas, A. (2019). In-situ evaluation for upgrading of biomass model compounds over noble metal catalysts by isotopic tracing and NMR monitoring. J. Anal. Appl. Pyrol. 137, 253-258. doi: 10.1016/j.jaap.2019.05.005

Chaala, A., Ba, T., Garcia-Perez, M., and Roy, C. (2004). Colloidal properties of biooils obtained by vacuum pyrolysis of softwood bark: aging and thermal stability. Energ. Fuel. 18, 1535-1542. doi: 10.1021/ef030156v

Diebold, J. P., and Czernik, S. (1997). Additives to lower and stabilize the viscosity of pyrolysis oils during storage. Energ. Fuel. 11, 1081-1091. doi: $10.1021 /$ ef9700339

Elliott, D. C., Oasmaa, A., Preto, F., Meier, D., and Bridgwater, A. V. (2012). Results of the IEA round robin on viscosity and stability of fast pyrolysis bio-oils. Energ. Fuel. 26, 3769-3776. doi: 10.1021/ef300384t study, due to the absence of acids, no obvious reaction was observed in the aldol condensation reaction section and phenol and aldehyde reaction section; the reactions for aldehydes were observed. Sugar and sugar derivatives showed high tendency toward condensation reaction in the presence of acids. Especially for HMF, this chemical presented totally different reaction mechanisms with the aid of different acids due to the multiple functional groups of HMF.

\section{DATA AVAILABILITY STATEMENT}

The original contributions presented in the study are included in the article/supplementary materials, further inquiries can be directed to the corresponding author/s.

\section{AUTHOR CONTRIBUTIONS}

RW and $\mathrm{HB}$ contributed to the conception and design of the study. RW performed the statistical analysis and wrote the first draft of the manuscript. All authors contributed to manuscript revision and read and approved the submitted version.

\section{FUNDING}

The authors would like to acknowledge the financial support from the National Science Foundation of China [51706044], the Natural Science Foundation of the Jiangsu of China [BK20170666], and the Recruitment Program for Young Professionals in China.

\section{SUPPLEMENTARY MATERIAL}

The Supplementary Material for this article can be found online at: https://www.frontiersin.org/articles/10.3389/fenrg. 2020.00079/full\#supplementary-material

Helle, S., Bennett, N. M., Lau, K., Matsui, J. H., and Duff, S. J. B. (2007). A kinetic model for production of glucose by hydrolysis of levoglucosan and cellobiosan from pyrolysis oil. Carbohyd. Res. 342, 2365-2370. doi: 10.1016/j.carres.2007.07.016

Hu, X., Wang, Y., Mourant, D., Gunawan, R., Lievens, C., Chaiwat, W., et al. (2013). Polymerization on heating up of bio-oil: a model compound study. AIChE J. 59, 888-900. doi: 10.1002/aic.13857

Huang, X., Korányi, T. I., Boot, M. D., and Hensen, E. J. M. (2014). Catalytic depolymerization of lignin in supercritical ethanol. ChemSusChem 7, 2276-2288. doi: 10.1002/cssc.201402094

Jo, H., Verma, D., and Kim, J. (2018). Excellent aging stability of upgraded fast pyrolysis bio-oil in supercritical ethanol. Fuel 232, 610-619. doi: 10.1016/j.fuel.2018.06.005

Joseph, J., Rasmussen, M. J., Fecteau, J. P., Kim, S., Lee, H., Tracy, K. A., et al. (2016). Compositional changes to low water content bio-oils during aging: an NMR, GC/MS, and LC/MS study. Energ. Fuel. 30, 4825-4840. doi: 10.1021/acs.energyfuels.6b00238

Kibet, J., Khachatryan, L., and Dellinger, B. (2012). Molecular products and radicals from pyrolysis of lignin. Environ. Sci. Technol. 46, 12994-13001. doi: 10.1021/es302942c

Luo, D., Yin, W., Liu, S., Yang, N., Xia, S., and Ma, P. (2018). Pyrolysis oil polymerization of water-soluble fraction during accelerated aging. Fuel 230, 368-375. doi: 10.1016/j.fuel.2018.05.017 
Ma, W., Liu, B., Zhang, R., Gu, T., Ji, X., Zhong, L., et al. (2018). Co-upgrading of raw bio-oil with kitchen waste oil through fluid catalytic cracking (FCC). Appl. Energ. 217, 233-240. doi: 10.1016/j.apenergy.2018.02.036

Meng, J., Moore, A., Tilotta, D., Kelley, S., and Park, S. (2014). Toward understanding of bio-oil aging: accelerated aging of bio-oil fractions. ACS Sustain. Chem. Eng. 2, 2011-2018. doi: 10.1021/sc500223e

Mu, W., Ben, H., Ragauskas, A., and Deng, Y. (2013). Lignin pyrolysis components and upgrading-technology review. Bioenerg. Res. 6, 1183-1204. doi: 10.1007/s12155-013-9314-7

Naske, C. D., Polk, P., Wynne, P. Z., Speed, J., Holmes, W. E., and Walters, K. B. (2012). Postcondensation filtration of pine and cottonwood pyrolysis oil and impacts on accelerated aging reactions. Energ. Fuel. 26, 1284-1297. doi: 10.1021/ef200541d

Oasmaa, A., and Kuoppala, E. (2003). Fast pyrolysis of forestry residue. 3. storage stability of liquid fuel. Energ. Fuel. 17, 1075-1084. doi: 10.1021/ef030011o

Patil, S. K. R., Heltzel, J., and Lund, C. R. F. (2012). Comparison of structural features of humins formed catalytically from glucose, fructose, and 5-hydroxymethylfurfuraldehyde. Energ. Fuel. 26, 5281-5293. doi: 10.1021/ef3007454

Patil, S. K. R., and Lund, C. R. F. (2011). Formation and growth of humins via aldol addition and condensation during acid-catalyzed conversion of 5hydroxymethylfurfural. Energ. Fuel. 25, 4745-4755. doi: 10.1021/ef2010157

Qu, T., Guo, W., Shen, L., Xiao, J., and Zhao, K. (2011). Experimental study of biomass pyrolysis based on three major components: hemicellulose, cellulose, and lignin. Ind. Eng. Chem. Res. 50, 10424-10433. doi: 10.1021/ie1025453

Ragauskas, A. J. (2006). The path forward for biofuels and biomaterials. Science 311, 484-489. doi: 10.1126/science.1114736

Vinu, R., and Broadbelt, L. J. (2012). A mechanistic model of fast pyrolysis of glucose-based carbohydrates to predict bio-oil composition. Energy Environ. Sci. 5, 9808-9826.
Wu, Y-m., Zhao, Z-L., Li, H-b. (2009). Low temperature pyrolysis characteristics of major components of biomass. J. Fuel Chem. Technol. 37, 427-432. doi: 10.1016/S1872-5813(10)60002-3

Yang, Z., Kumar, A., and Huhnke, R. L. (2015). Review of recent developments to improve storage and transportation stability of biooil. Renew. Sust. Energy Rev. 50, 859-870. doi: 10.1016/j.rser.2015. 05.025

Yu, Y., Chua, Y. W., and Wu, H. (2016). Characterization of pyrolytic sugars in bio-oil produced from biomass fast pyrolysis. Energ. Fuel. 30, 4145-4149. doi: 10.1021/acs.energyfuels.6b00464

Yu, Y., Xu, P., Xing, J., Li, L., and Chang, J. (2018). Investigation of aging performance of bio-oil phenol-formaldehyde resin with the treatment of artificial accelerated aging method. Polym. Eng. Sci. 58, 1810-1816. doi: $10.1002 /$ pen. 24785

Zhang, S., Zhang, H., Liu, X., Zhu, S., Hu, L., and Zhang, Q. (2018). Upgrading of bio-oil from catalytic pyrolysis of pretreated rice husk over Fe-modified ZSM5 zeolite catalyst. Fuel Process. Technol. 175, 17-25. doi: 10.1016/j.fuproc.2018. 03.002

Conflict of Interest: The authors declare that the research was conducted in the absence of any commercial or financial relationships that could be construed as a potential conflict of interest.

Copyright (c) 2020 Wang and Ben. This is an open-access article distributed under the terms of the Creative Commons Attribution License (CC BY). The use, distribution or reproduction in other forums is permitted, provided the original author(s) and the copyright owner(s) are credited and that the original publication in this journal is cited, in accordance with accepted academic practice. No use, distribution or reproduction is permitted which does not comply with these terms. 